\title{
DEVELOPMENT OF AN AUTOMATIC SHIELD EXCAVATION SYSTEM
}

\author{
Tatsuo Sato \\ Kajima Corporation \\ Mechanical Engineering Development Section \\ Machinery \& Equipment Department \\ Construction Group \\ Kajima Corporation \\ 2-7, Motoakasaka 1-chome \\ Minato-ku,Tokyo,Japan 107
}

\begin{abstract}
The posture of the shield machine must be accurately controlled for constructing a tunnel on the planned line in shield constructions. This posture control consists of the "Linear Excavation Alignment Control" that decides the progress of excavation and the "Directional Correction" that decides the mode of operation. We have developed a new "Automatic Shield Excavation System" for automatic posture control of the shield machine during shield excavating operations. This system is reported here.

\section{Outline of the System}

The "Automatic Shield Excavation System" that we have developed, consists of the "Automatic Measuring Sub-system" and the "Direction Control Sub-system." The system makes use of a light wave distance measuring and angle measuring model (from here onward called "total station"), and detectors such as gyro compass, inclinometer and stroke gauge. The automatic measuring sub-system measures the position and posture of the shield machine in real time during the operation, and monitors data such as displacement in position angle from the planned line. The direction control sub-system estimates the excavation path on and after the next ring, based on the data of the automatic measuring sub-system, and controls the posture of the shield machine by correcting the direction with automatically selecting the jack pattern. Table 1 shows the comparison of various types of automatic measuring systems. This system uses a combination of the total station and the gyro compass. The prerequisite of this system is the monitoring of positions at particular ring intervals by control surveys (underground surveys) for daily control during automatic excavating operations.
\end{abstract}


Table 1. Comparison of Automatic Measuring Systems (cont'd)

\begin{tabular}{|c|c|c|c|}
\hline System & Gyro Compass System & $\begin{array}{c}\text { Optical Survey } \\
\text { Instrument System } \\
\text { (light wave) }\end{array}$ & $\begin{array}{c}\text { Combination of Gyro } \\
\text { and Optical (light } \\
\text { wave)System }\end{array}$ \\
\hline Cause of Error & 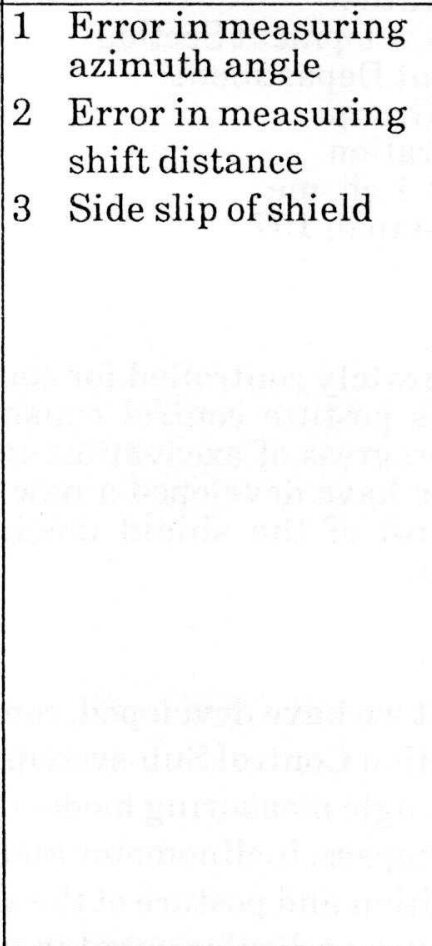 & \begin{tabular}{|ll}
1 & $\begin{array}{l}\text { Positional error in } \\
\text { total station }\end{array}$ \\
& * \\
& Installation \\
& error during \\
& transfer \\
$*$ & Shift of \\
& segment \\
$*$ & Error in \\
& installation of \\
& the prism. \\
2 & Distance \\
measurement & error \\
3 & Error in the \\
& measurement of \\
& projected angle
\end{tabular} & 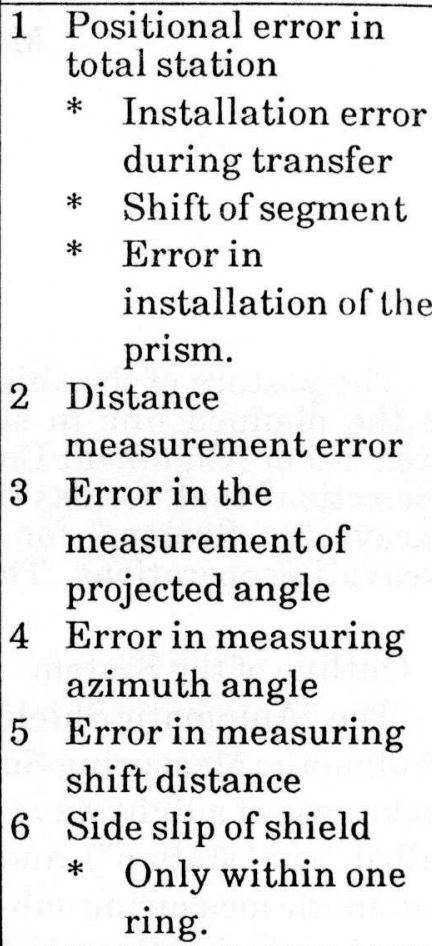 \\
\hline $\begin{array}{l}\text { Suitability for } \\
\text { straight lines }\end{array}$ & $\begin{array}{l}\text { No limitations for } \\
\text { alignment. }\end{array}$ & $\begin{array}{l}\text { Not suited for sharply } \\
\text { curved } \\
\text { lines.(Transfers will } \\
\text { increase) }\end{array}$ & $\begin{array}{l}\text { Not suited for sharply } \\
\text { curved lines.(Transfers } \\
\text { will increase) }\end{array}$ \\
\hline $\begin{array}{l}\text { Suitability of } \\
\text { Cross Section }\end{array}$ & $\begin{array}{l}\text { Shield diameter: More } \\
\text { than } \$ 1000 \mathrm{~mm} \\
\text { Installation position: } \\
\text { No limitations }\end{array}$ & $\begin{array}{l}\text { Shield diameter: } \\
\text { More than } \$ 3000 \\
\text { mm } \\
\text { Installation position: } \\
\text { Space for light waves } \\
\text { to pass is necessary. }\end{array}$ & $\begin{array}{l}\text { Shield diameter: More } \\
\text { than } \phi 3000 \mathrm{~mm} \\
\text { Installation position: } \\
\text { Space for light waves to } \\
\text { pass is necessary. }\end{array}$ \\
\hline Applicability & $\begin{array}{l}\text { Ideal for small and } \\
\text { medium bores, curved } \\
\text { line constructions. }\end{array}$ & $\begin{array}{l}\text { Ideal for medium and } \\
\text { large bores, straight } \\
\text { line and gentle } \\
\text { curved line } \\
\text { constructions. }\end{array}$ & $\begin{array}{l}\text { Ideal for medium and } \\
\text { large bores, straight } \\
\text { line and gentle curved } \\
\text { line constructions. }\end{array}$ \\
\hline Remarks & $\begin{array}{l}\text { Periodic checks and } \\
\text { surveys are necessary. }\end{array}$ & $\begin{array}{l}\text { Measures for } \\
\text { preventing cut-off of } \\
\text { light wave during } \\
\text { excavation,are } \\
\text { necessary. }\end{array}$ & \\
\hline
\end{tabular}


Table 1. Comparison of Automatic Mesuring Systems

\begin{tabular}{|c|c|c|c|}
\hline System & Gyro Compass System & $\begin{array}{c}\text { Optical Survey } \\
\text { Instrument System } \\
\text { (light wave) }\end{array}$ & $\begin{array}{c}\text { Combination of Gyro } \\
\text { and Optical (light } \\
\text { wave)System }\end{array}$ \\
\hline Instrument used & Gyro compass & $\begin{array}{l}\text { Total station + } \\
\text { reflecting prism }\end{array}$ & $\begin{array}{l}\text { Gyro compass + total } \\
\text { station + reflecting } \\
\text { prism }\end{array}$ \\
\hline $\begin{array}{l}\text { Measurement } \\
\text { principles }\end{array}$ & $\begin{array}{l}\text { The azimuth angle of } \\
\text { the shield machine is } \\
\text { detected. From the } \\
\text { azimuth angle and shift } \\
\text { distance of the shield } \\
\text { machine, the } \\
\text { cumulative } \\
\text { displacement from a } \\
\text { particular start position } \\
\text { is calculated. Then the } \\
\text { coordinates of the } \\
\text { machine are found. }\end{array}$ & $\begin{array}{l}\text { The distance from the } \\
\text { total station to the } \\
\text { reflecting prism } \\
\text { installed on the } \\
\text { machine is measured. } \\
\text { Simultaneously, the } \\
\text { coordinates of the } \\
\text { reflecting prizm are } \\
\text { measured. The } \\
\text { coordinates of the } \\
\text { position of the } \\
\text { machine are found } \\
\text { from the relations } \\
\text { between the position } \\
\text { of the machine and } \\
\text { the installed position } \\
\text { of the prism. }\end{array}$ & $\begin{array}{l}\text { The coordinates of the } \\
\text { reflecting prism are } \\
\text { measured by the optical } \\
\text { system. The coordinates } \\
\text { of the machine position } \\
\text { are found. The } \\
\text { measurements with the } \\
\text { optical system are } \\
\text { carried out at fixed } \\
\text { intervals. Interpolation } \\
\text { between the intervals is } \\
\text { carried out by shift } \\
\text { calculations using the } \\
\text { gyro system. }\end{array}$ \\
\hline \begin{tabular}{|l|} 
Position \\
Identification
\end{tabular} & $\begin{array}{l}\text { Identified as relative } \\
\text { coordinates from the } \\
\text { start position. In } \\
\text { principle, the errors up } \\
\text { to the check survey will } \\
\text { be accumulated. } \\
\end{array}$ & $\begin{array}{l}\text { Identified as the } \\
\text { absolute coordinates } \\
\text { of the prism. }\end{array}$ & $\begin{array}{l}\text { Identified as the } \\
\text { absolute coordinates of } \\
\text { the prism. }\end{array}$ \\
\hline $\begin{array}{l}\text { Measurement } \\
\text { Interval }\end{array}$ & Short & Long & $\begin{array}{l}\text { Short (while } \\
\text { excavating) }\end{array}$ \\
\hline
\end{tabular}




\section{System Configuration and Functions}

\section{(1) Overall Configuration}

Fig. 1 shows the outline drawing of the system. As shown in the figure, the system consists of detectors installed in the shield machine, such as the gyro compass, the inclinometer and the jack length gauge. It also consists of the total station to be installed in the tunnel, multiplex transmission equipment and the data processing computer installed in the central control room. Table 2 shows the main equipment used and their specifications.

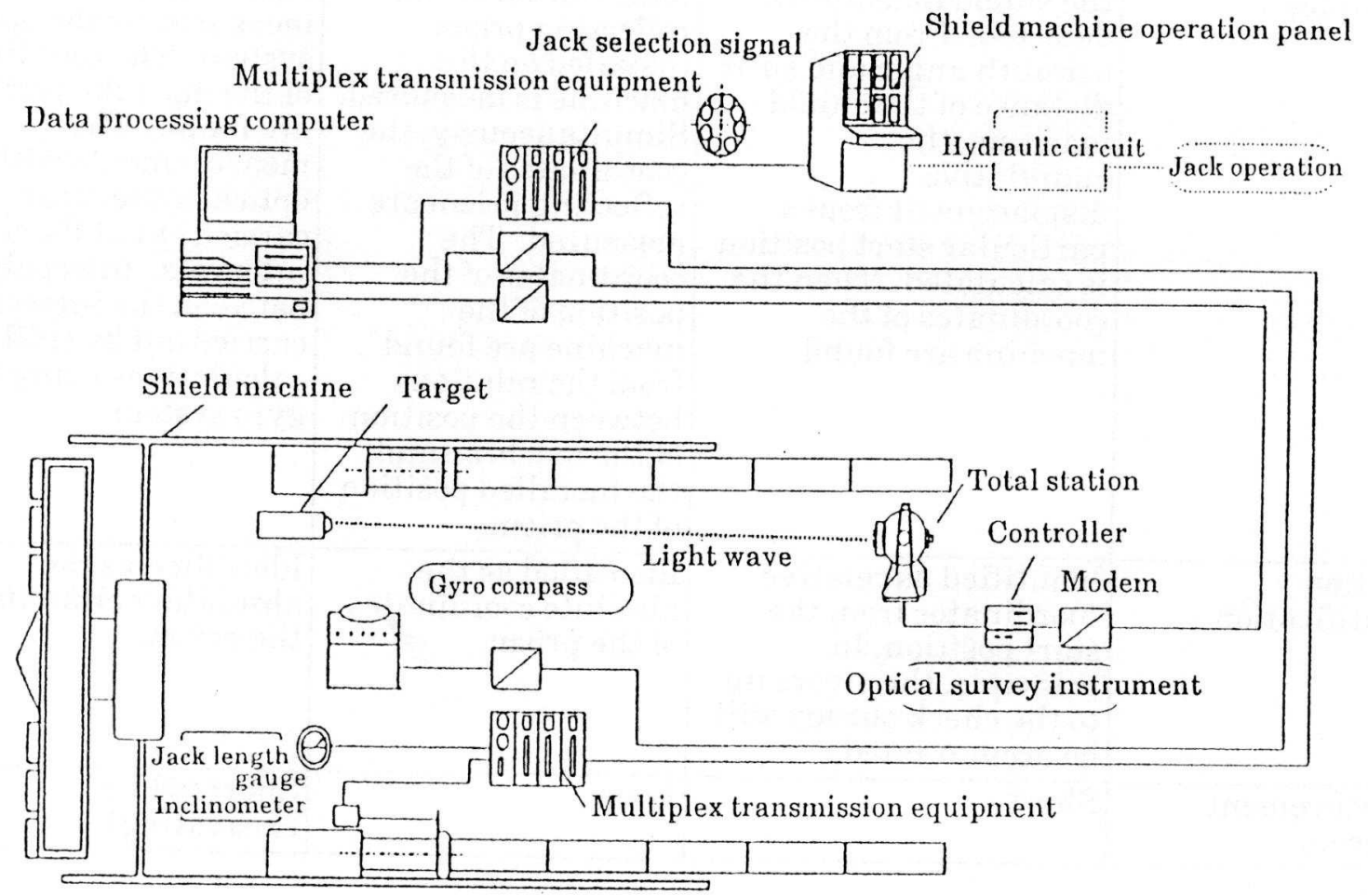

Fig. 1 System Configuration Diagram 
Table 2 Specifications of Equipment

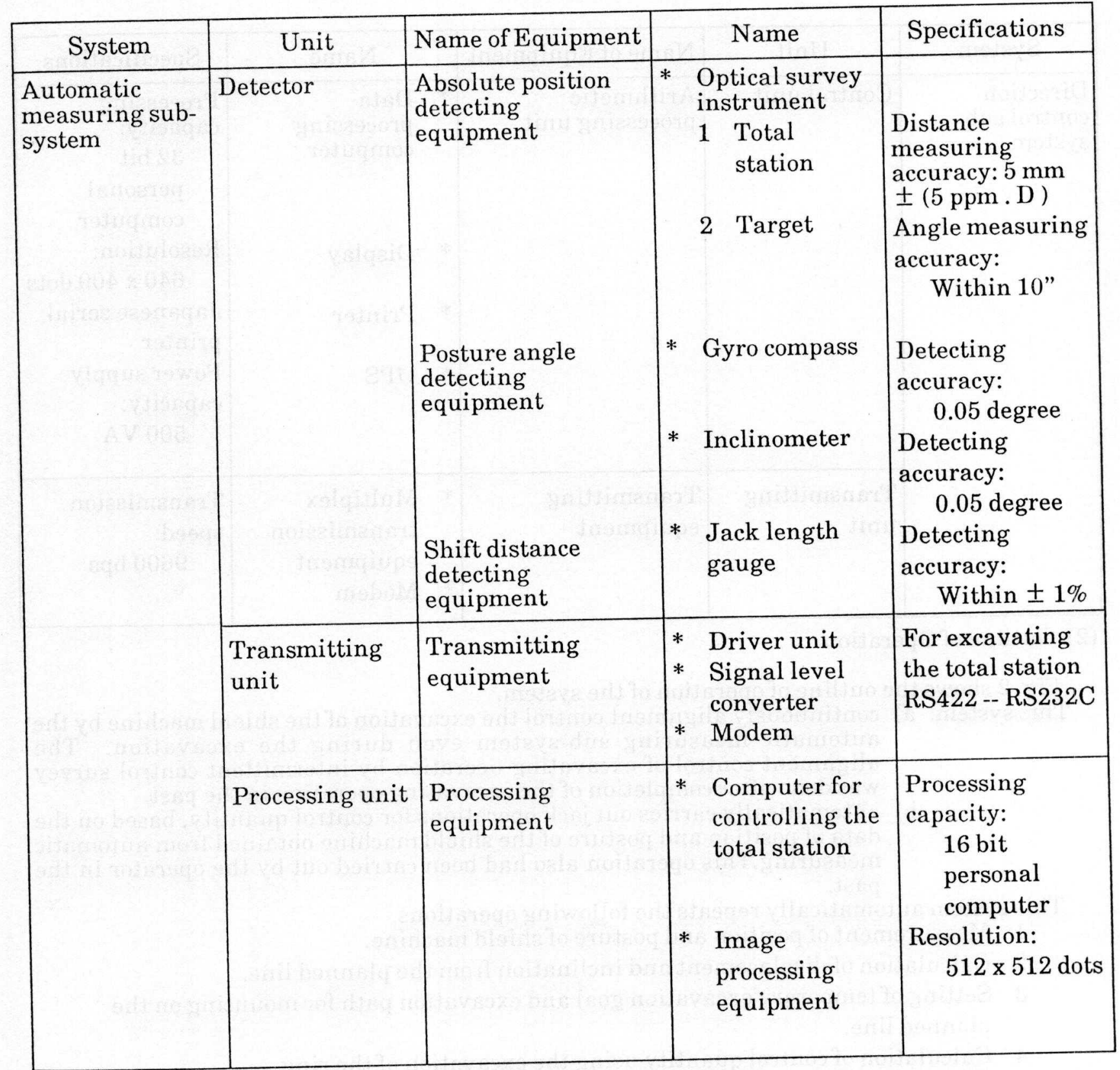


Table 2 Specifications of Equipment (cont'd)

\begin{tabular}{|c|c|c|c|c|}
\hline System & Unit & Name of Equipment & Name & Specifications \\
\hline \multirow[t]{2}{*}{$\begin{array}{l}\text { Direction } \\
\text { control sub- } \\
\text { system }\end{array}$} & Control unit & $\begin{array}{l}\text { Arithmetic } \\
\text { processing unit }\end{array}$ & $\begin{array}{ll}* & \begin{array}{l}\text { Data } \\
\text { processing } \\
\text { computer }\end{array} \\
* & \text { Display } \\
* & \text { Printer } \\
* & \text { UPS }\end{array}$ & $\begin{array}{l}\text { Processing } \\
\text { capacity: } \\
\quad 32 \text { bit } \\
\quad \text { personal } \\
\text { computer } \\
\text { Resolution: } \\
\quad 640 \text { x } 400 \text { dots } \\
\text { Japanese serial } \\
\text { printer } \\
\text { Power supply } \\
\text { capacity: } \\
500 \text { VA }\end{array}$ \\
\hline & $\begin{array}{l}\text { Transmitting } \\
\text { unit }\end{array}$ & $\begin{array}{l}\text { Transmitting } \\
\text { equipment }\end{array}$ & $\begin{array}{ll}* & \text { Multiplex } \\
\text { transmission } \\
\text { equipment } \\
* \text { Modem }\end{array}$ & $\begin{array}{l}\text { Transmission } \\
\text { speed: } \\
\quad 9600 \mathrm{bps}\end{array}$ \\
\hline
\end{tabular}

(2) Outline of Operation

Fig. 2 shows the outline of operation of the system.

This system: a) continuously alignment control the excavation of the shield machine by the automatic measuring sub-system even during the excavation. The alignment control of excavating operation by intermittent control survey was done after completion of the excavating operation in the past.

b) automatically carries out jack operations for control quantity, based on the data of position and posture of the shield machine obtained from automatic measuring.This operation also had been carried out by the operator in the past.

This system automatically repeats the following operations.

1 Measurement of position and posture of shield machine.

2 Calculation of displacement and inclination from the planned line.

3 Setting of temporary excavation goal and excavation path for mounting on the planned line.

4 Calculation of control quantity using the excavation of the ring.

5 Selection of jack pattern by calculation.

6 Output of the selected jack pattern.

* $\quad 1 \sim 2$ Automatic measuring sub-system

3 6 Direction control sub-system 


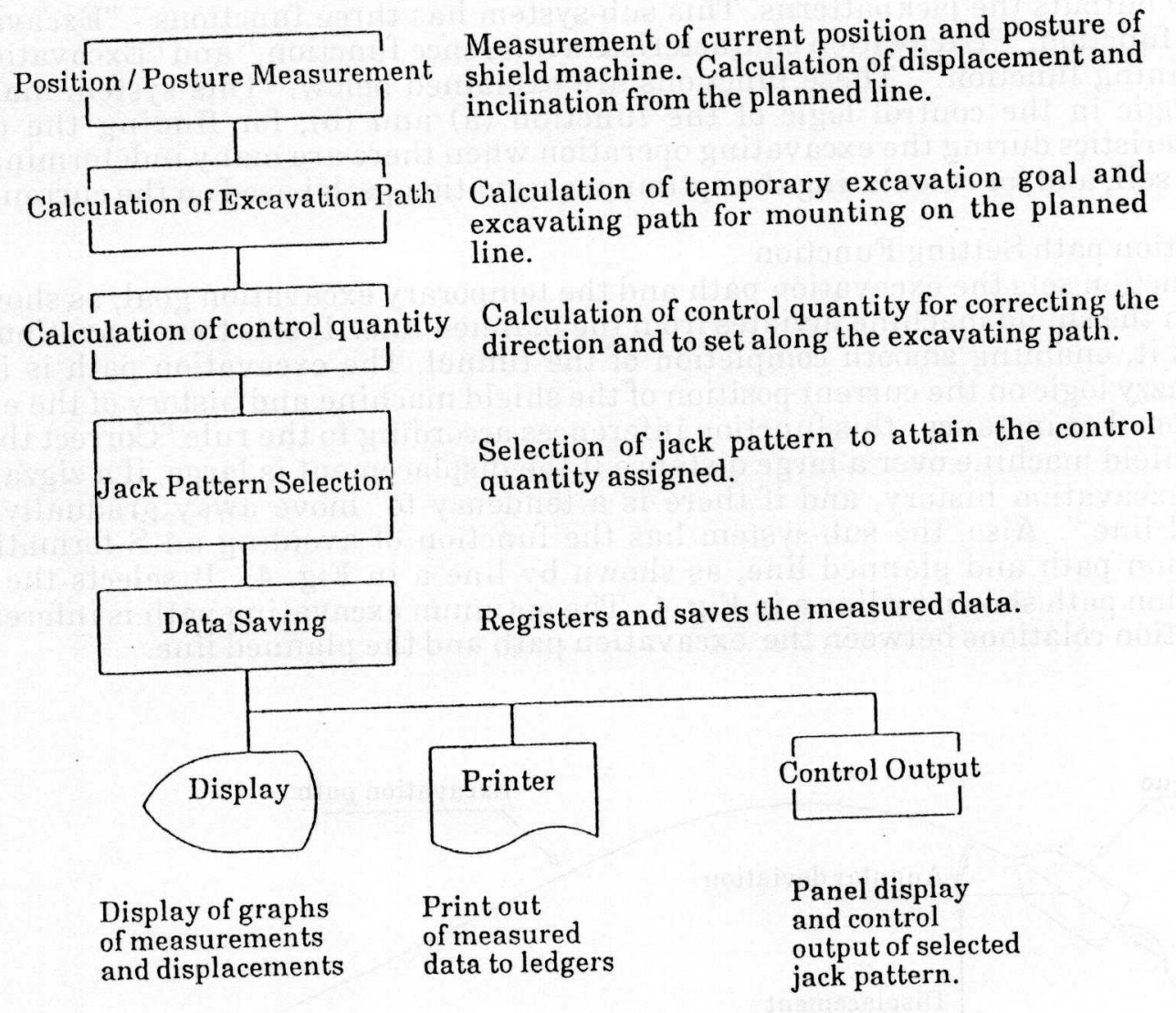

Fig. 2 Outline of System Operations

(3) Sub-system Functions

a Automatic Measuring Sub-system

The automatic measuring sub-system makes use of the survey instruments installed in the shield machine and the already set tunnel. It measures the position and posture of the shield machine during the excavating operation in real time.

(a) Position Identification Function

This function identifies the position of the shield machine in $(x, y, z)$ coordinates for a coordinate system that has been arbitrarily set on site for finding the position of the shield machine with respect to the survey reference point.The target in the shield machine is automatically surveyed using the total station installed in the tunnel. 'This enables the absolute position of the shield machine to be identified.This absolute measurement is carried out every 5 seconds while 1 ring is driven. Within the interval, interpolation is done using the relative shifts found from the shift quantity and azimuth angle (gyro compass) and the angle of inclination (pitching gauge).

(b) Displacement and Angular Displacement Identification Function

This function identifies the position and the posture of the shield machine with respect to the planned line. It identifies the displacement (left/right, up/down) and the angular displacement (pitching, rolling, yawing) of the shield machine from the planned line. 
b. Automatic Direction Control Sub-system

The automatic direction control sub-system sets the excavation path based on the data of the planned line and position of shield machine, obtained from the automatic measuring sub-system. It calculates the control quantity for excavating along the excavation path and selects / outputs the jackpatterns. This sub-system has three functions - "Excavation path setting function," "Excavation characteristics inference function," and "Excavation method determining function." These functions are explained below. This system makes use of fuzzy logic in the control logic of the function (a) and (b), for finding the change in characteristics during the excavating operation when there are many indeterminate factors such as soil, and for calculating the optimum excavation path based on the current status.

(a) Excavation path Setting Function

This function sets the excavation path and the temporary excavation goal, as shown in Fig. 3 , when the shield machine diviates from the planned line. It sets the excavation path and corrects it, enabling smooth completion of the tunnel. The excavation path is inferenced using fuzzy logic on the current position of the shield machine and history of the excavating operation. For instance, this function inferences according to the rule "Correct the position of the shield machine over a large distance if the displacement is large, if a zigzag is found in the excavation history, and if there is a tendency to move away gradually from the planned line." Also, the sub-system has the function of avoiding an S formation of the excavation path and planned line, as shown by line a in Fig. 4. It selects the optimum excavation path shown by line a in Fig. 4 . The optimum excavating path is inferenced from the position relations between the excavation path and the planned line.

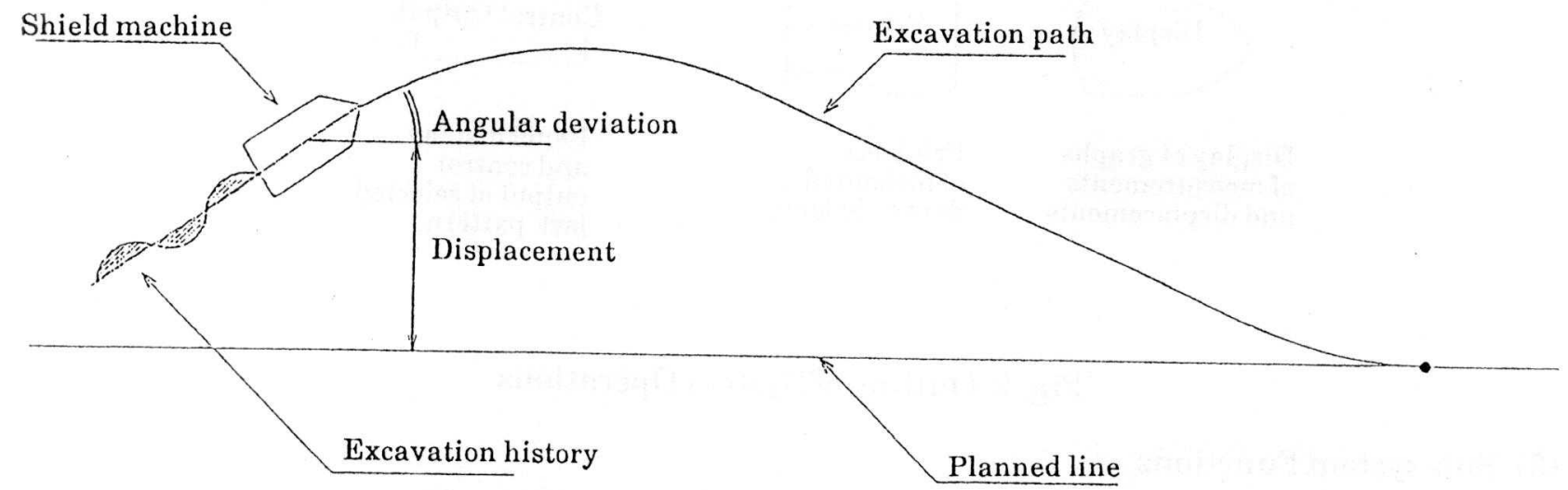

Fig. 3 Setting of planned excavating line (1)

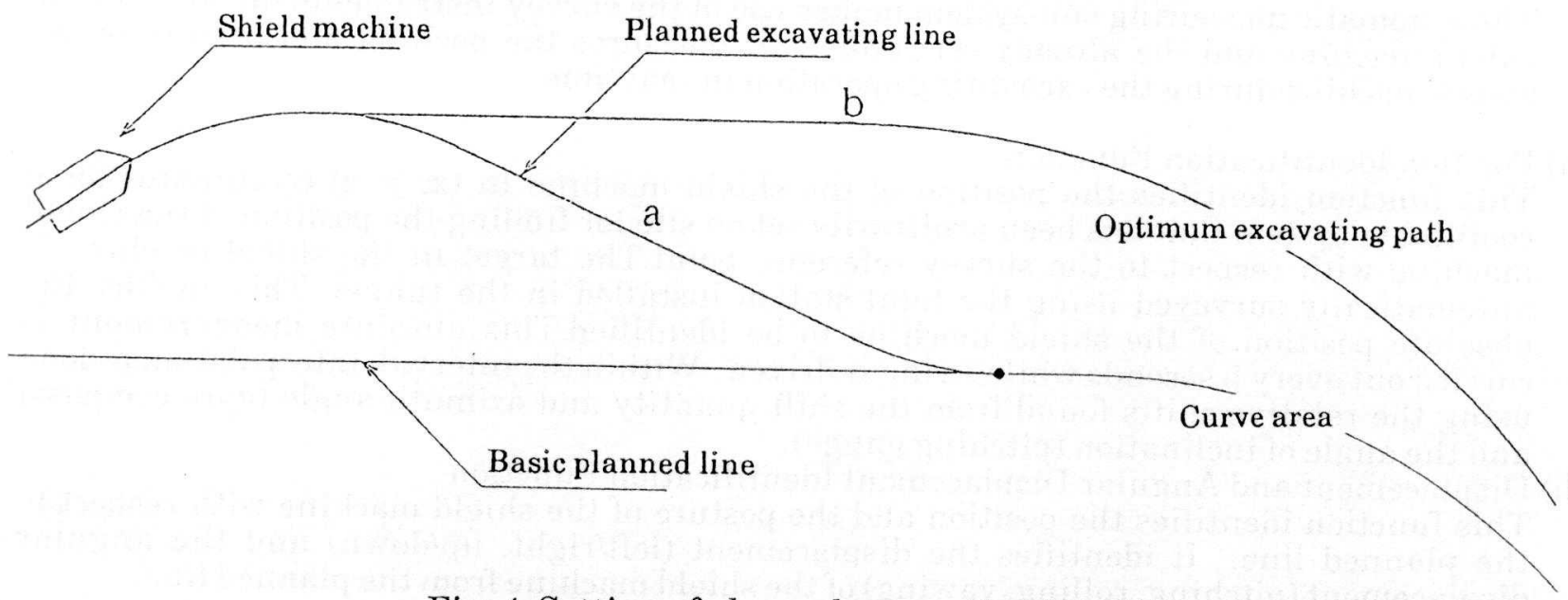

Fig. 4 Setting of planned excavating line (2) 


\section{(b) Excavation Characteristics Inference Function}

This function realizes controls to suit the conditions. It extracts the changes in excavating characteristics due to changes in soil or excavating conditions, which vary with time.

For instance, as shown in Fig. 5, the modeling of characteristics by equations, such as "enabling the shielding machine to be turned easily, using the copy cutter used in the past few excavating operations for widening the overcut, compared to the situation when copy cutter is not used," is extremely difficult. This function expresses the characteristic mentioned above, as the characteristic angle, using fuzzy logic. The detailed deduction items are status of usage of the copy cutter in the past excavating operations and status of control quantities and the actual characteristics.

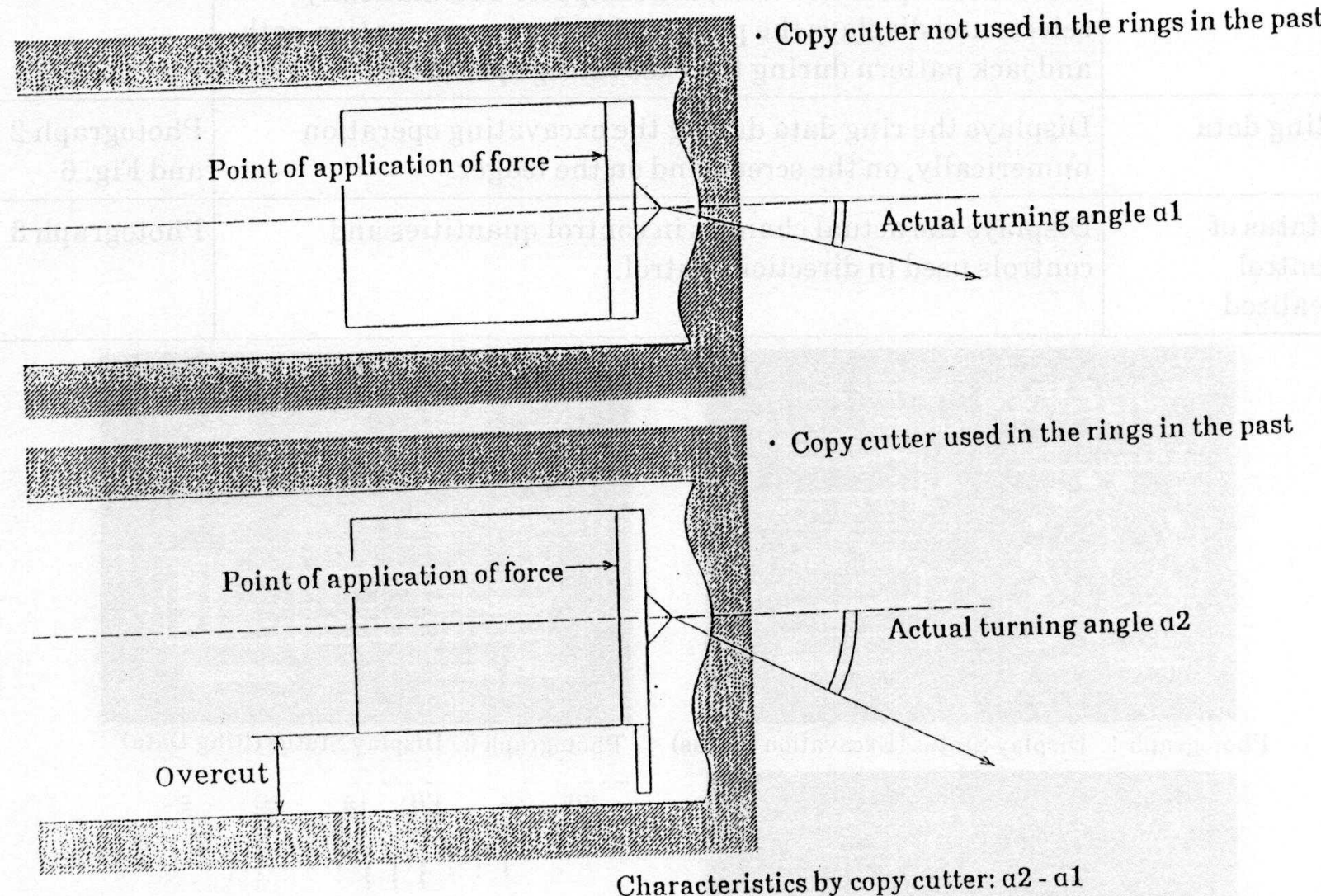

Fig. 5 Concept of Excavation Characteristics using the Copy Cutter

(c) Excavation Method Determining Function

This function creates control output following the set excavating path so that the shield machine reaches the temporary excavation goal. It calculates the control quantity for direction control and selects the jack pattern that suits thiscontrol quantity.

The control quantity is determined by overall judgement, considering the current posture of the shield machine,position relation between the planned line and excavation path , characteristic angle and current tail clearance of the shield machine.

(d) Processing Program

The processing program monitors the excavating status within one ring and makes control calculations. The program is in C language and stored in the disk. Table 3, Photograph $1-3$ show the description and status of the data displays of the system. 
Table 3 Data Processing Status

\begin{tabular}{|l|l|l|}
\hline Display Screen & \multicolumn{1}{|c|}{ Description } & Display Status \\
\hline $\begin{array}{l}\text { Excavation } \\
\text { Status }\end{array}$ & $\begin{array}{l}\text { Displays the numeric data of position and posture of the } \\
\text { shield machine with respect to the planned line on the } \\
\text { screen. Identifies the position and posture of shield } \\
\text { machine to operator. Also, the computer automatically } \\
\text { selects and displays the predicted optimum excavation path } \\
\text { and jack pattern during the excavating operation. }\end{array}$ & Photograph 1 \\
\hline $\begin{array}{l}\text { Ring data } \\
\text { Displays the ring data during the excavating operation } \\
\text { numerically, on the screen and on the ledger. }\end{array}$ & $\begin{array}{l}\text { Photograph } 2 \\
\text { and Fig. 6 }\end{array}$ \\
\hline $\begin{array}{l}\text { Status of } \\
\text { control } \\
\text { realized }\end{array}$ & $\begin{array}{l}\text { Displays the actual changes in control quantities and } \\
\text { controls used in direction control. }\end{array}$ & Photograph 3 \\
\hline
\end{tabular}

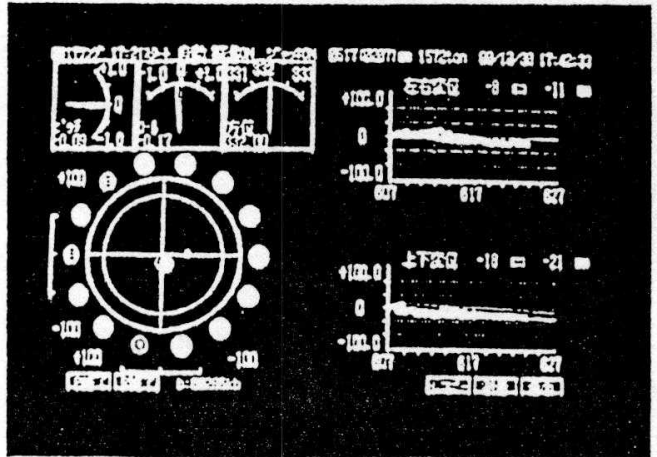

Photograph 1. Display Status (Excavation Status)

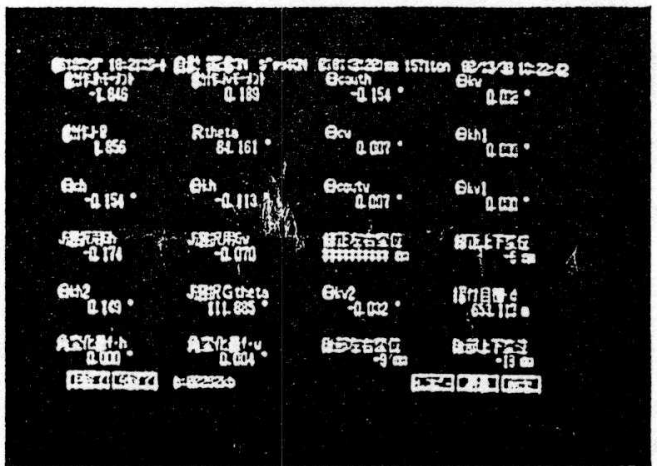

Photograph 3. Display Status (Control Realization Status) 3. Coriclusion

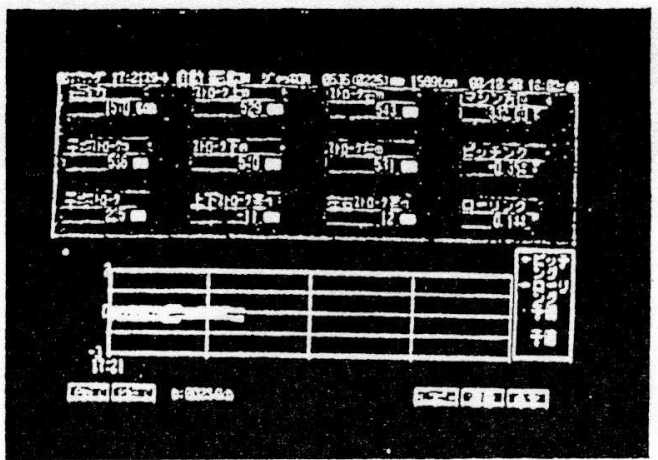

Photograph 2. Display Status (Ring Data)

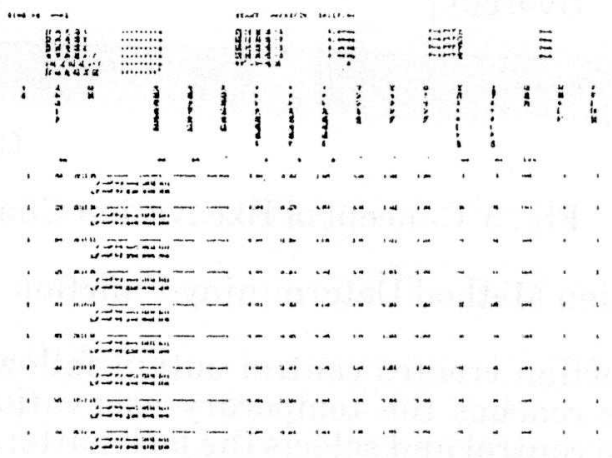

Fig. 6 Display Status (Print Out)

We have developed an automatic control system using the personal computer with the objective of attaining efficiency in shield operations. Allowances in shield operations and controls performed conventionally by experienced operators, can be automatically performed now. Robotization in shield operations is our next goal. In future, we will investigate more efficient systems for processing and handling complex models of shield machines such as the special shield machine. We will strive to make the system easier to use in future. We will aim for a total system that includes control of earth pressure and slurry also. 